\title{
Ice Recrystallization Inhibiting Polymers Enable Glycerol-Free Cryopreservation of Microorganisms
}

\author{
Muhammad Hasan, ${ }^{\dagger+}$ Alice E. R. Fayter, ${ }^{\dagger}$ and Matthew I. Gibson ${ }^{*}, \dagger, \ddagger$ \\ ${ }^{\dagger}$ Department of Chemistry and ${ }^{\ddagger}$ Warwick Medical School, University of Warwick, Gibbet Hill Road, Coventry CV4 7AL, U.K.
}

Supporting Information

ABSTRACT: All modern molecular biology and microbiology is underpinned by not only the tools to handle and manipulate microorganisms but also those to store, bank, and transport them. Glycerol is the current goldstandard cryoprotectant, but it is intrinsically toxic to most microorganisms: only a fraction of cells survive freezing and the presence of glycerol can impact downstream applications and assays. Extremophile organisms survive repeated freeze/thaw cycles by producing antifreeze proteins which are potent ice recrystallization inhibitors. Here we introduce a new concept for the storage/transport of microorganisms by using ice recrystallization inhibiting poly(vinyl alcohol) in tandem with poly(ethylene glycol). This cryopreserving formulation is shown to result in a 4-fold increase in E. coli yield post-thaw, compared to glycerol, utilizing lower concentrations, and successful cryopreservation shown as low as 1.1 wt $\%$ of additive. The mechanism of protection is demonstrated to be linked not only to inhibiting ice recrystallization (by comparison to a recombinant antifreeze protein) but also to the significantly lower toxicity of the polymers compared to glycerol. Optimized formulations are presented and shown to be broadly applicable to the cryopreservation of a panel of Gram-negative, Gram-positive, and mycobacteria strains. This represents a step-change in how microorganisms will be stored by the design of new macromolecular ice growth inhibitors; it should enable a transition from traditional solvent-based to macromolecular microbiology storage methods.

\section{INTRODUCTION}

Bacteria and their study underpin all research in infectious diseases, microbiology, and structural and molecular biology as well as being crucial in biotechnology and food processes (notably probiotics). A key challenge with any biotechnology or cell-based processes is the logistics-the storage, transport, distribution, and recovery of intact and viable cells suitable for purpose, with no pheno/genotype alterations. Continuous culture is rarely practical; thus, lyophilization and cryopreservation are commonly employed in both academic and industrial settings. ${ }^{1,2}$ Cryopreservation, ${ }^{3,4}$ especially in research laboratories, is the most commonly used, as no infrastructure (other than $\mathrm{a}-80{ }^{\circ} \mathrm{C}$ freezer or liquid nitrogen $\left(-196{ }^{\circ} \mathrm{C}\right)$ ) is required, ensuring it is easy to use, whereas lyophilization requires optimization and more specialized equipment/ formulations. The storage of bacteria for supplements such as probiotics is growing, and recent research into the microbiome points toward its involvement in a host of medical disorders including, but not limited to, irritable bowel syndrome, depression, cardiovascular disease, and obesity, showing the significant need for strategies to store bacteria, ${ }^{5-8}$ especially if microbiome transplants become a reality for the treatment of drug-resistant infections, for example. ${ }^{9}$

Cryopreservation traditionally requires the addition of organic solvents to mitigate the damage caused by ice formation and growth as well as membrane rupture and osmotic stress which would otherwise lead to cell death. ${ }^{10,11}$ For mammalian cells, dimethyl sulfoxide (DMSO) is the most widely employed cryoprotectant for both slow freezing and vitrification (depending on the DMSO concentration), and for bacteria, glycerol is typically used. While very successful and used globally these are not perfect solutions. They require high concentrations (10-25 wt \%), the solvents can potentially have cytotoxic effects necessitating careful addition and rapid removal (post-thaw) to maintain viability, ${ }^{12,13}$ and they do not lead to quantitative recovery of all cells, as such there is a need to investigate innovative cryopreservation methods.

Extremophile organisms have evolved many strategies to enable them to survive in ice-rich environments, providing inspiration for new biomimetic strategies to improve cryopreservation. ${ }^{14,15}$ For example, Arctic fish species produce a diverse range of antifreeze proteins (AFPs) which function to limit ice growth by ice recrystallization inhibition (IRI). ${ }^{16-18}$ AFPs are not suitable for many applications though, as they cannot be produced readily on a large scale, and their secondary effect of dynamic ice shaping can lead to reduced cell recovery post-thaw. ${ }^{19,20}$ Furthermore, biomedical applications are hampered due to lack of sufficient immunological/

Received: April 23, 2018

Revised: June 20, 2018

Published: June 22, 2018 
toxicological data. Therefore, synthetic macromolecular mimics of AFPs have emerged, which can reproduce their properties but benefit from the scalable and tunable synthesis of synthetic polymers. ${ }^{18,21,22}$ These have been used to enhance the cryopreservation of mammalian cells including blood, ${ }^{23-25}$ cell lines, ${ }^{26}$ and primary cells. ${ }^{27,28}$ Their primary function is ice recrystallization inhibition, where the rate of growth (not formation) of ice is slowed, leading to reduced cell death during thawing. The most active polymer mimics reported to date are based on not only poly(vinyl alcohol) ${ }^{29-34}$ but also Safranin-O, ${ }^{35}$ poly(ampholyte)s, ${ }^{36,37}$ and glycopeptides. ${ }^{38}$ However, there are no reports, to the best of our knowledge, on applying IRI-active materials to the challenge of bacterial cryopreservation, with only a report of nonfreezing stabilization due to freezing point depression, which is a distinct process for nonfreezing storage. ${ }^{39}$

This paper takes inspiration from extremophile organisms to demonstrate successful bacterial cryopreservation using a unique all-polymer, glycerol-free, formulation. This formulation benefits from a synergistic effect of an ice growth inhibiting polymer with a secondary hydrophilic polymer, and they outperform the current gold-standard glycerol, leading to increased cell yields at low cryoprotectant concentrations.

\section{EXPERIMENTAL SECTION}

Bacteria Growth. Escherichia coli TOP10 cells, Bacillus subtilis (WT168), and Mycobacterium smegmatis (Mc2155) were chosen for freezing as three different types of bacteria with different cell structures. E. coli and B. subtilis were grown in Lysogeny broth (LB) medium containing $100 \mu \mathrm{g} \mathrm{mL}^{-1}$ ampicillin, and M. smegmatis was grown in $7 \mathrm{H} 9$ broth base at $37{ }^{\circ} \mathrm{C}$ with a stirring rate of $180 \mathrm{rpm}$.

Ice Recrystallization Inhibition (Splat) Assay. A $10 \mu \mathrm{L}$ droplet of cryoprotectant in PBS solution is dropped from $1.4 \mathrm{~m}$ onto a glass microscope coverslip on top of an aluminum plate cooled to $-78{ }^{\circ} \mathrm{C}$ using dry ice. Upon impact with the plate the droplet instantly freezes, spreading out and forming a thin wafer of ice. This wafer is then placed on a liquid nitrogen cooled cryostage cooled to $-8{ }^{\circ} \mathrm{C}$. The wafer is then left to anneal for $30 \mathrm{~min}$ at $-8{ }^{\circ} \mathrm{C}$. Three photographs are then taken of the wafer in different locations at $20 \times$ zoom under cross-polarizers. The longest grain crystals as well as the total number of crystals in the image are counted using ImageJ; the area of the field of view divided by this number of crystals gives the average crystal size per wafer, which is reported as a \% of area compared to PBS control.

Freezing Protocols. Different molecular weight PEGs $(100 \mathrm{mg}$ $\mathrm{mL}^{-1}$; $200 \mathrm{Da}, 400 \mathrm{Da}, 1.5 \mathrm{kDa}, 4 \mathrm{kDa}, 6 \mathrm{kDa}$, and $8 \mathrm{kDa}$ ) and PVAs (1 mg mL $\mathrm{mL}^{-1}$ 10, 23, and $31 \mathrm{kDa}$ ) were dissolved in PBS for comparison in cryoprotective activity alongside poly(isopropenyl acetate-alt-maleic anhydride) functionalized with (dimethylamino)ethanol (poly(ampholyte)), AFPIII, and glycerol. After growing each of the bacteria until OD600, cells $(150 \mu \mathrm{L})$ were added to separate solutions of the different cryoprotectants $(150 \mu \mathrm{L})$ in $1.5 \mathrm{~mL}$ vials and snap frozen in liquid nitrogen before thawing at $25{ }^{\circ} \mathrm{C}$ in a water bath for $5 \mathrm{~min}$. The freeze-thaw (FT) cycles were repeated seven times, and then the samples were added to LB in 96-well plates $(200 \mu \mathrm{L})$. Serial dilutions took place, and the samples were plated on ampicillin plates. These were left to grow at $37^{\circ} \mathrm{C}$ for subsequent colony counts. Confocal microscopy was performed to evaluate the number of live/ dead cells obtained. When storage at $-20{ }^{\circ} \mathrm{C}$ was to be assessed, samples were prepared similarly up until they were snap frozen in liquid nitrogen, after which they were directly stored at $-20{ }^{\circ} \mathrm{C}$.

Cryoprotectant Toxicity. Equal volumes of bacteria and cryoprotectant solutions were left shaking at $4{ }^{\circ} \mathrm{C}$ overnight. The cryoprotectant samples $(20 \mu \mathrm{L})$ were then added to LB in wells $(200$ $\mu \mathrm{L}$ ) in the first column of 96-well plates, and serial dilutions of the samples were produced by transferring $20 \mu \mathrm{L}$ from column 1 to column 2 , mixing, and then taking $20 \mu \mathrm{L}$ from column 2 to column 3 . This was repeated until column 7 was reached, giving dilutions up to
$10^{-7}$. Dilutions $10^{-2}-10^{-5}$ were plated on ampicillin plates, and colonies were grown at $37{ }^{\circ} \mathrm{C}$ for subsequent counting. Toxicity assays were repeated using three PEG concentrations $(100,50$, and 10 $\mathrm{mg} \mathrm{mL}^{-1}$ ) combined with a constant PVA concentration of 0,1 , or 10 $\mathrm{mg} \mathrm{mL} \mathrm{m}^{-1}$.

Cellular Growth Profile. Toxicity and protection of cells in liquid culture were studied using absorbance spectroscopy. Samples were prepared as before and underwent seven FT cycles. The cells were then grown in LB $(200 \mathrm{~mL})$ over $14 \mathrm{~h}$ under continuous shaking at 37 ${ }^{\circ} \mathrm{C}$, and their $\mathrm{OD}$ was measured at $600 \mathrm{~nm}$ at $10 \mathrm{~min}$ intervals and compared to a control sample that underwent no freeze-thaw cycles. This growth assay was performed also on cells combined with different AFP concentrations $\left(0.1,2.5\right.$, and $\left.5 \mathrm{mg} \mathrm{mL}^{-1}\right)$ for comparison as well as samples frozen at $-20^{\circ} \mathrm{C}$ as well as $-196{ }^{\circ} \mathrm{C}$.

Live/Dead Bacterial Viability Test. Following seven freezethaw cycles using the indicated conditions, samples were isolated at $10000 \mathrm{~g}$ for $10 \mathrm{~min}$, and the supernatant was discarded. An aliquot was taken prior to the freeze-thaw cycle as a live cell control, and a further aliquot was heat killed (incubated at $80{ }^{\circ} \mathrm{C}$ for $30 \mathrm{~min}$ ) for a dead cell control. Cells were resuspended in $20 \mu \mathrm{L}$ of $0.85 \% \mathrm{NaCl}$ solution. $10 \mu \mathrm{L}$ of this suspension was diluted in $200 \mu \mathrm{L}$ of $0.85 \%$ $\mathrm{NaCl}$ solution, and the samples were incubated at room temperature for $1 \mathrm{~h}$. Samples were pelleted at $10000 \mathrm{~g}$ for $10 \mathrm{~min}$, the supernatant was discarded, and the cells were resuspended in $100 \mu \mathrm{L}$ of $0.85 \%$ $\mathrm{NaCl}$ solution. Next, the LIVE/DEAD bacterial viability staining mixture was prepared by mixing SYTO-9 and propidium iodide to final concentrations of 1.67 and $10 \mathrm{mM}$, respectively. The cells were stained by adding $0.3 \mu \mathrm{L}$ of the staining solution to $100 \mu \mathrm{L}$ of cell suspension and incubating in the dark for $15 \mathrm{~min}$ (at room temperature). Slides for microscopy were prepared by trapping 5 $\mu \mathrm{L}$ of the stained bacterial suspension between a slide and a coverslip. Samples were then analyzed by means of fluorescent microscopy (at either $100 \times$ or $60 \times$ magnification) using GFP (excitation $470 / 40 \mathrm{~nm}$, emission 525/50 nm) and mCherry (excitation $560 / 40 \mathrm{~nm}$, emission $630 / 75 \mathrm{~nm}$ ) filter sets to visualize the SYTO-9 and propidium iodide staining, respectively.

\section{RESULTS AND DISCUSSION}

The primary aim of this study was to evaluate the role of ice recrystallization inhibiting (IRI) polymers to enable solventfree cryopreservation of bacteria. A range of synthetic polymers were selected for this based on their previous use in mammalian cell cryopreservation: poly(vinyl alcohol), PVA, which is a potent IRI; poly(ethylene glycol), PEG, which has no IRI but was chosen to provide a hydrophilic "bulking" agent which has been shown to be important for blood cell cryopreservation; $^{40,41}$ a poly(ampholyte) $(\mathrm{p}(\mathrm{amph}))$, which has a weaker IRI activity than PVA; ${ }^{25,42}$ and recombinant AFPIII, an antifreeze protein originally isolated from ocean pout $^{43}$ (Figure 1A). It is important to note that PVA and PEG were particularly of interest as they are low-cost (comparable to glycerol), are available in a range of molecular weights, and are produced to food/clinical grades, making them ideal for translational applications. ${ }^{44}$ The polymers' IRI activity was evaluated by a modified splat assay (Figure $1 \mathrm{~B}-\mathrm{G}$ ). Briefly, ice wafers were nucleated to give small $(<10 \mu \mathrm{m})$ ice crystals, which were allowed to grow for $30 \mathrm{~min}$ and then measured. Smaller ice crystals indicated more IRI activity, reported as the mean largest grain size (MGLS). The concentrations chosen for the IRI assays related to those used in cryopreservation experiments. Detailed studies on their IRI activity have been reported previously, and a comparison is shown in Figure S3 (Supporting Information). ${ }^{29,36}$

To evaluate the performance of these IRI active polymers versus glycerol, a series of cryopreservation experiments were undertaken. E. coli was added to different cryoprotective 
A<smiles>OCC(O)CO</smiles>

Glycerol

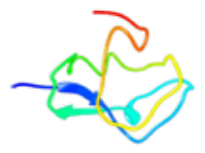

AFP III
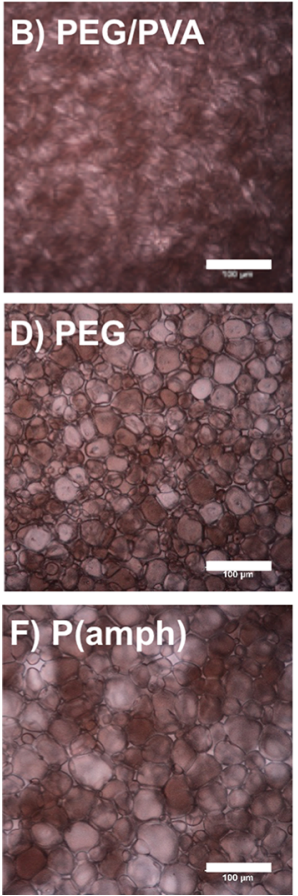

Figure 1. Cryoprotectants used and IRI activity at concentrations relevant for this work. (A) Chemical structures. Cryomicrographs of ice wafers grown in the presence of (B) $100 \mathrm{mg} \mathrm{mL}^{-1} 4 \mathrm{kDa}$ PEG + 1 $\mathrm{mg} \mathrm{mL}^{-1} 10 \mathrm{kDa}$ PVA, (C) $1 \mathrm{mg} \mathrm{mL}^{-1} 10 \mathrm{kDa}$ PVA, (D) $100 \mathrm{mg}$ $\mathrm{mL}^{-1} 4 \mathrm{kDa}$ PEG, (E) $1 \mathrm{mg} \mathrm{mL}^{-1}$ AFPIII, (F) $50 \mathrm{mg} \mathrm{mL}^{-1}$ poly(ampholyte), and (G) PBS control. Scale bar $=100 \mu \mathrm{m}$.

formulations and then exposed to seven freeze-thaw cycles from liquid nitrogen $\left(-196{ }^{\circ} \mathrm{C}\right)$ to room temperature $\left(20^{\circ} \mathrm{C}\right)$, and the number of colony forming units determined by growth on agar plates for $16 \mathrm{~h}$ was recorded (Figure 2A). This was chosen to mimic laboratory conditions where stocks are often frozen and thawed during routine use. $25 \%$ glycerol resulted in an average of 15 recovered colonies compared to 1 for no added cryoprotectant. PVA, AFP, and the poly(ampholyte) alone gave results identical to those with no cryoprotectant added. (It should be noted that the concentrations of each of the above were chosen based on their relative IRI activity to give similar effects, not at equal mass concentration to enable us to correlate the physical properties to the observed biological responses.) Our previous work using red blood cells (which also have no nucleus, like bacteria) has shown that IRI active polymers increased post-thaw recovery only when used in combination with a hydrating secondary cryoprotectant such as polymer gels or hydroxyethyl starch. ${ }^{40,41}$ PEG was therefore added (due to biocompatibility and commercial availability), and the mixture PEG/PVA (100 $\mathrm{mg} \mathrm{mL}^{-1}+1 \mathrm{mg}$ $\mathrm{mL}^{-1}$ ) was found to dramatically increase recovery to 69
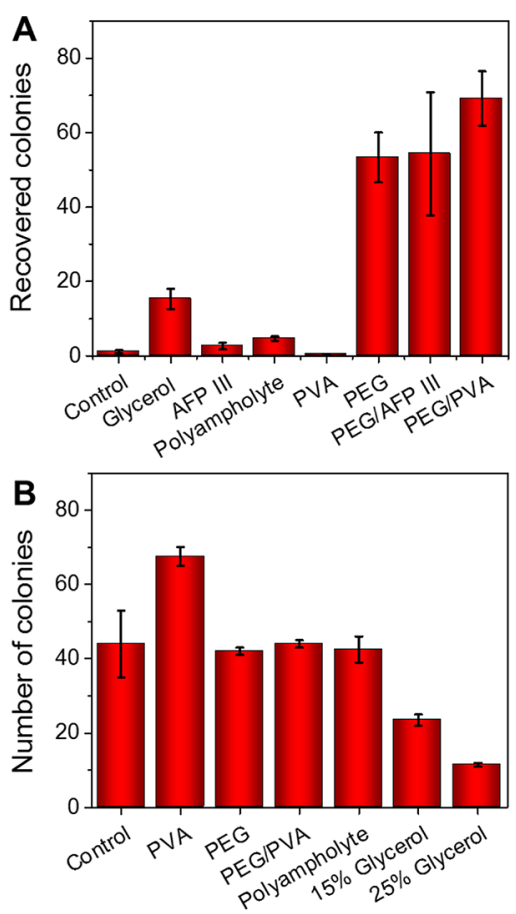

Figure 2. (A) Recovered colonies of E. coli after seven freeze (-196 $\left.{ }^{\circ} \mathrm{C}\right)$-thaw $\left(20^{\circ} \mathrm{C}\right)$ cycles. (B) Recovered colonies of E. coli after overnight incubation with cryoprotectants. Concentrations of cryoprotectants: [glycerol] $=25 \mathrm{wt} \%$; $\mathrm{AFPIII}]=1 \mathrm{mg} \mathrm{mL} \mathrm{m}^{-1}$; $[\mathrm{PVA}]=1 \mathrm{mg} \mathrm{mL}^{-1}$; $[\mathrm{PEG} / \mathrm{AFPIII}]=100+0.01 \mathrm{mg} \mathrm{mL}^{-1} ;[\mathrm{PEG} /$ PVA $]=100+1 \mathrm{mg} \mathrm{mL}^{-1} ;[$ poly $($ ampholyte $\left.)]=50 \mathrm{mg} \mathrm{mL}^{-1}\right)$. Control is LB media alone.

colony forming units, which is a $>4$-fold increase compared to glycerol alone. PEG/AFP mixtures lead to similar results (52 colonies), supporting the hypothesis that controlling IRI is the key mechanism in protecting bacteria during cryopreservation, by reducing ice growth especially during thawing. The poly(ampholyte)s, however, showed no cryoprotective effect, despite them previously being used for mammalian cells, where they appear to function via cell membrane interactions. ${ }^{37}$ Poly(ampholyte)s have far weaker IRI than PVA or AFPs, and hence this supports a mechanism of protection based on limiting ice recrystallization rather than membrane plasticization/stabilization. In order to test whether there is a significant difference between the recovery obtained from PEG/PVA versus that obtained from PVA alone, a two-sample $t$ test was performed, and it was concluded that the difference between them was statistically significant (Tables S1 and S2, Supporting Information).

A key challenge associated with the use of glycerol is its intrinsic toxicity at cryopreservation concentrations, so the impact of incubating the polymers with E. coli compared to glycerol was evaluated. Each component (at the indicated cryopreservation concentration) was incubated with E. coli overnight at $4{ }^{\circ} \mathrm{C}$, and subsequently the number of colony forming units was determined (Figure 2B). Glycerol at 15 or $25 \mathrm{wt} \%$ led to a significant reduction in recovered colonies. Conversely, none of the polymers showed toxicity to the E. coli. The increase in recovered colonies for PVA could be due to some metabolism of the polymer. This supports our hypothesis that biomimetic macromolecular antifreezes are "spectator additives" which only function when ice is present and are 
ignored by microorganisms (and indeed other cells) which is crucial for downstream applications.

To further optimize this formulation, the PEG concentration was varied from 100 to $10 \mathrm{mg} \mathrm{mL}^{-1}$, all with addition of $1 \mathrm{mg}$ $\mathrm{mL}^{-1}$ PVA, and the number of recovered colonies after seven freeze-thaw cycles was counted (Figure 3A). Reducing the

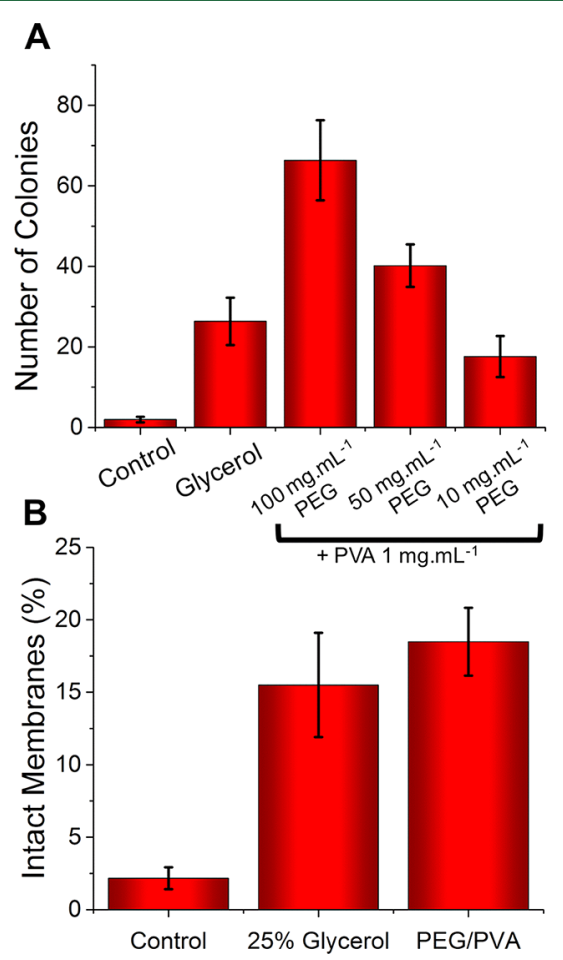

Figure 3. (A) Effect of varying PEG concentration on number of recovered E. coli colonies after seven freeze $\left(-196^{\circ} \mathrm{C}\right)$-thaw $\left(20^{\circ} \mathrm{C}\right)$ cycles. (B) Live/dead viability testing on E. coli immediately after freeze-thaw cycle, with percentage of green (intact membrane) bacteria determined by confocal microscopy. $[\mathrm{PEG} / \mathrm{PVA}]=100+1$ $\mathrm{mg} \mathrm{mL} \mathrm{m}^{-1}$. Error bars represent SD from six repeats.

concentration of PEG to 50 and $10 \mathrm{mg} \mathrm{mL}^{-1}$ led to a significant reduction in the number of colonies recovered compared to $100 \mathrm{mg} \mathrm{mL}^{-1}$. However, it is important to note that $10 \mathrm{mg} \mathrm{mL}^{-1}$ PEG with $1 \mathrm{mg} \mathrm{mL}^{-1}$ PVA is just a $1.1 \mathrm{wt} \%$ solution but performs equally to $25 \mathrm{wt} \%$ glycerol, which represents a remarkable cryopreservation outcome with a 25fold reduction in cryoprotectant. It shows that while there is an optimum formulation, there is scope to vary the components and hence supporting ease of use in a realistic laboratory situation. In some downstream applications (such as food) lowering cryoprotectants concentration, rather than maximizing total cell recovery, is desirable, and this new polymer-only formulation is clearly suitable.

The above experiments relied on counting colony-forming units, which shows the application but does not give insight into the mechanisms of cell stress during freeze-thaw. To assess the bacteria immediately after thawing, confocal microscopy was employed with a live/dead viability assay which measures the integrity of cell membranes (Figure 3B and Figure S11). Bacterial cells with intact cell membranes exhibit green fluorescence (SYTO-9 dye) while those with compromized cell membranes exhibit red fluorescence (propidium iodide dye). Following freeze/thaw in PBS alone just $2.2 \%$ of the $E$. coli had intact membranes (green), demonstrating that ice growth causes significant mechanical damage. Post-freeze/thaw in either $25 \%$ glycerol or PEG/PVA resulted in $15-18 \%$ of the $E$. coli retaining intact membranes. These observations suggest that the mechanisms of cryoinjury of both glycerol and our macromolecular antifreezes are very similar. However, the colony counting results (Figure 2) confirmed the polymer approach to be superior, supporting a hypothesis that the reduced toxicity of the polymers means that more and healthier colonies can grow post-thaw, and reduced growth inhibition compared to glycerol.

Additional bacterial strains for cryopreservation were selected to cover a wide range of genera to ensure these effects are not unique to E. coli. Bacillus subtilis was chosen as a Gram-positive strain and Mycobacterium smegmatis as a mycobacteria (distinct cell wall compared to other Grampositives) for further analysis. Using the same conditions as for E. coli, the cells were exposed to seven freeze-thaw cycles, and the recovered colonies were counted (Table 1). To enable comparison of the data and to account for the different growth rates of each bacterial strain, the recovered colonies were also normalized to the highest recovery (Figure 4).

In all cases, the PEG/PVA mixture gave equal or better levels of recovery than glycerol alone. It was noted that $M$. smegmatis (which is a slow-growing organism compared to other two) gave fewer colonies after a fixed period of growth in all conditions, but the PEG/PVA still matched the performance of glycerol. In some cases, the PEG alone gave favorable recovery levels also (as any uncharged solute will give some protection), but in all cases addition of PVA increased this recovery, showing it is an essential component to ensure recovery of viable cells, without resorting to multiple rounds of

Table 1. Mean Colonies Recovered after Seven Freeze-Thaw Cycles ${ }^{a}$

\begin{tabular}{|c|c|c|c|c|c|c|}
\hline & \multicolumn{2}{|c|}{ E. coli } & \multicolumn{2}{|c|}{ M. smegmatis } & \multicolumn{2}{|c|}{ B. subtilis } \\
\hline & total & normalized (\%) & total & normalized (\%) & total & normalized (\%) \\
\hline control & $1 \pm 0.4$ & 1 & $4 \pm 0.5$ & 12 & $29 \pm 10.4$ & 11 \\
\hline $25 \%$ glycerol & $15 \pm 2.8$ & 22 & $30 \pm 6.0$ & 88 & $93 \pm 18.9$ & 35 \\
\hline AFPIII & $3 \pm 0.9$ & 4 & $2 \pm 0.3$ & 6 & $26 \pm 6.7$ & 10 \\
\hline PVA & $0 \pm 0.1$ & 0 & $3 \pm 1.5$ & 9 & $5 \pm 0.7$ & 2 \\
\hline PEG & $53 \pm 6.7$ & 77 & $28 \pm 4.3$ & 82 & $150 \pm 10.7$ & 57 \\
\hline PEG/PVA & $69 \pm 7.3$ & 100 & $34 \pm 4.2$ & 100 & $262 \pm 39.3$ & 100 \\
\hline poly(ampholyte) & $5 \pm 0.6$ & 7 & $28 \pm 4.5$ & 82 & $20 \pm 5.0$ & 8 \\
\hline
\end{tabular}

${ }^{a}[$ Glycerol $]=25$ wt \%; $[\mathrm{PEG}]=100 \mathrm{mg} \mathrm{mL}^{-1} ;[\mathrm{PEG} / \mathrm{PVA}]=100+1 \mathrm{mg} \mathrm{mL}^{-1} ;[$ AFPIII $]=0.1 \mathrm{mg} \mathrm{mL}^{-1}$; poly $($ ampholyte $)=50 \mathrm{mg} \mathrm{mL}^{-1}$. Error represents the SD from six repeats. Note that the total colonies recovered for each organism vary based on their own growth rates; hence, normalized recovery (versus the highest recovery level) is also included. 


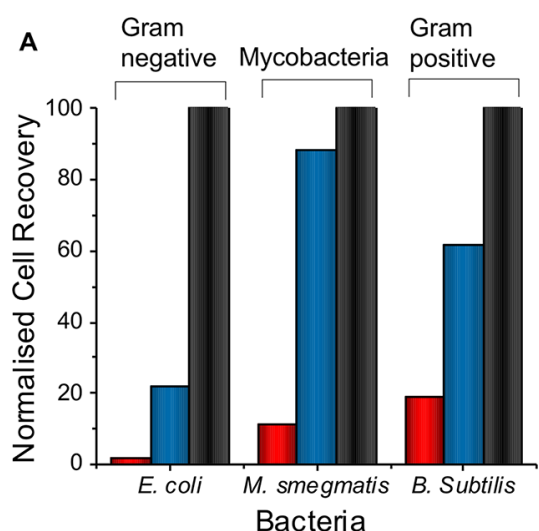

Figure 4. Normalized cell recovery for three different bacteria upon addition of different cryoprotectants after seven freeze $\left(-196{ }^{\circ} \mathrm{C}\right)-$ thaw $\left(20{ }^{\circ} \mathrm{C}\right)$ cycles $($ red $=$ control, blue $=$ glycerol, black $=$ PEG $/$ PVA). Values obtained are normalized to themselves.

freezing controls. These results demonstrate the versatile nature of this approach and that replacing glycerol in laboratories with this polymer formulation is a reliable way to match or improve current storage methods.

This macromolecular cryoprotection solution using iceinhibiting polymers is clearly suitable for bacteria storage, but there are many parameters which can be varied in this system including the molecular weight of the polymers and weight ratios. To enable a large number of conditions to be screened, the post-thaw growth rate of E. coli was also followed by $\mathrm{OD}_{600}$ (turbidity) measurements, which enable higher throughput measurements in 96-well plates. E. coli was frozen with the indicated formulations and post-thaw inoculated into LB media, and their growth was monitored. After seven freezethaw cycles in liquid nitrogen, cells cryopreserved in $25 \%$ glycerol and PEG/PVA (100 and $1 \mathrm{mg} \mathrm{mL}^{-1}$, respectively) had essentially identical growth rates (Figure 5), which were faster than all the other formulations used.

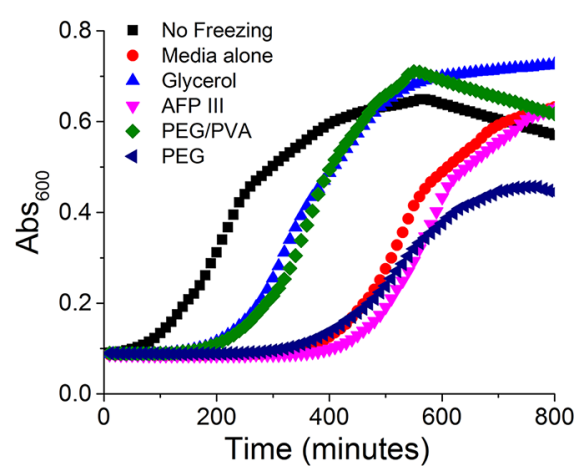

Figure 5. E. coli growth profiles after seven freeze $\left(-196^{\circ} \mathrm{C}\right)$-thaw $\left(20^{\circ} \mathrm{C}\right)$ cycles and then inoculation into LB media.

By monitoring growth profiles of $E$. coli, various formulations and molecular weights of PVA were also tested for their efficacy (Figures S5-S7). For PVA, 10 and $31 \mathrm{kDa}$ gave approximately identical recovery levels. However, $10 \mathrm{kDa}$ is easier to dissolve into buffer, making it preferable for real applications where concentrated stock solutions are required. Higher molecular weight PVA can also lead to dynamic iceshaping which is known to reduce recovery of cells postthaw. ${ }^{23}$ Lower molecular weight PEGs (200-1500 Da) alone appeared to have a slightly greater cryoprotective effect than larger PEGs (4-8 kDa), as they reach a higher OD600 and display slower logarithmic decline phases, indicating improved cell health, but these differences were small (Figure S6). Various permutations of PEG/PVA were also screened (Figure S7), and in all cases addition of PVA increased the cryoprotective effect and lengthened the stationary phase of cells. The improvement was most significant in the case of larger PEGs. Considering the cryoprotective effect of each of the mixtures, and the solubility of each of the constituents, it was determined that $10 \mathrm{kDa}$ PVA and $4 \mathrm{kDa}$ PEG were the optimum molecular masses out of the 18 formulations we tested to use to ensure reliable and easy to use cryopreservation.

As a final test, the effect of storage at $-20{ }^{\circ} \mathrm{C}$ in a standard laboratory freezer after first snap freezing $\left(-80^{\circ} \mathrm{C}\right)$ was also studied after 1 and 4 weeks of storage (Figure S4). It was found that bacterial recovery was similar for $25 \%$ glycerol and PEG/PVA after 1 week storage, which supports the use of this method for routine laboratory manipulations. For 4 week storage we noted that the glycerol formulation yielded more colonies, but this was not optimized, and significant recovery was still possible with the polymer-only mixture. It should be noted that the glycerol solution did not fully freeze at $-20^{\circ} \mathrm{C}$, thus providing a carbon source to the E. coli.

\section{CONCLUSIONS}

This study reports a disruptive approach to store bacteria in the frozen state through modulation of ice recrystallization with synthetic polymer formulations, which mimic antifreeze proteins used in nature to survive extreme environments. It is shown that PEG/PVA mixtures provide a synergistic effect with the number of recovered bacterial colonies after seven freeze-thaw cycles being up to 4-fold higher than the current gold standard of glycerol. Confocal microscopy showed that similar numbers of bacteria with intact membranes are recovered for both systems but that the polymer cryoprotectants lead to more viable colonies, suggesting their lower toxicity is crucial. This new cryopreservation approach is shown to be suitable for a range of bacterial genera including Gram-negative/positive and mycobacteria. It was found that the synergistic effect on cell survival was linked to PVAs ice recrystallization activity and the PEG bulking agent, as addition of type III antifreeze proteins (at similar total IRI activity) also enabled cryopreservation, although these proteins are significantly more expensive and not practical for routine cryopreservation compared to the polymer formulations. These results highlight the contrast with traditional solventbased cryoprotectants which function by distinct mechanisms. Optimal conditions for use of this system in a laboratory or application-focused environment are presented, and as both PEG and PVA are commodity polymers available as food grade, ${ }^{45,46}$ this system will have wide application across molecular biology, microbiome research, and for translation into the food or biotechnology industry, which are underpinned by the storage and transport of specific bacterial strains.

\section{ASSOCIATED CONTENT}

\section{S Supporting Information}

The Supporting Information is available free of charge on the ACS Publications website at DOI: 10.1021/acs.biomac.8b00660. 
Additional growth curves and experimental details (PDF)

\section{AUTHOR INFORMATION}

\section{Corresponding Author}

*(M.I.G.) E-mail m.i.gibson@warwick.ac.uk.

\section{ORCID $\odot$}

Alice E. R. Fayter: 0000-0001-9470-9560

Matthew I. Gibson: 0000-0002-8297-1278

\section{Notes}

The authors declare the following competing financial interest(s): M.I.G., M.H., and A.F. are co-inventors on a patent filed relating to the cryopreservation of cells as described in this work.

\section{ACKNOWLEDGMENTS}

M.I.G. holds an ERC starting grant (CRYOMAT 638661). The Royal Society is also thanked for funding the cryomicroscopes used in this study. The Midlands Integrative Biosciences Doctoral Training Partnership (MIBTP) is thanked for a studentship for Julia Lipecki (BB/M01116X/ 1) which provided assistance with confocal microscopy. We also thank Peter Davies (Queen's University, Kingston, Canada) for providing the genetic construct encoding for AFPIII from ocean pout (rQAE isoform, M1.1HISPET20b), C. Stubbs for providing the poly(ampholyte), Dr. E. Denham for providing the Bacillus subtilis, Dr. E. Fullam for providing the Mycobacterium smegmatis, and Mohammed Ridwan Rahman for designing the image for the table of contents.

\section{REFERENCES}

(1) Heylen, K.; Hoefman, S.; Vekeman, B.; Peiren, J.; De Vos, P. Appl. Microbiol. Biotechnol. 2012, 94 (3), 565-574.

(2) Reddy, K. B. P. K.; Awasthi, S. P.; Madhu, A. N.; Prapulla, S. G. Food Biotechnol. 2009, 23 (3), 243-265.

(3) Mazur, P. Science (Washington, DC, U. S.) 1970, 168 (3934), 939-949.

(4) Mazur, P. Cryobiology 2010, 60 (1), 4-10.

(5) Wang, Z.; Klipfell, E.; Bennett, B. J.; Koeth, R.; Levison, B. S.; DuGar, B.; Feldstein, A. E.; Britt, E. B.; Fu, X.; Chung, Y.-M.; Wu, Y.; Schauer, P.; Smith, J. D.; Allayee, H.; Tang, W. H. W.; DiDonato, J. A.; Lusis, A. J.; Hazen, S. L. Nature 2011, 472 (7341), 57-63.

(6) Sharon, G.; Sampson, T. R.; Geschwind, D. H.; Mazmanian, S. K. Cell 2016, 167 (4), 915-932.

(7) Rea, K.; Dinan, T. G.; Cryan, J. F. Neurobiol. Stress 2016, 4, $23-$ 33.

(8) Navaneetharaja, N.; Griffiths, V.; Wileman, T.; Carding, S. J. Clin. Med. 2016, 5 (6), 55.

(9) Manichanh, C.; Reeder, J.; Gibert, P.; Varela, E.; Llopis, M.; Antolin, M.; Guigo, R.; Knight, R.; Guarner, F. Genome Res. 2010, 20 (10), 1411-1419.

(10) Zachariassen, K. E.; Kristiansen, E. Cryobiology 2000, 41, 257279.

(11) Tedeschi, R.; De Paoli, P. In Methods in Biobanking; Dillner, J., Ed.; Humana Press: Totowa, NJ, 2011; pp 313-326.

(12) Shu, Z.; Heimfeld, S.; Gao, D. Bone Marrow Transplant. 2014, 49 (4), 469-476.

(13) Capicciotti, C. J.; Kurach, J. D. R.; Turner, T. R.; Mancini, R. S.; Acker, J. P.; Ben, R. N. Sci. Rep. 2015, 5, 9692.

(14) Pikuta, E. V.; Hoover, R. B.; Tang, J. Crit. Rev. Microbiol. 2007, 33 (3), 183-209.

(15) Møbjerg, N.; Halberg, K. A.; Jørgensen, A.; Persson, D.; Bjørn, M.; Ramløv, H.; Kristensen, R. M. Acta Physiologica; Blackwell Publishing Ltd: Oxford, UK, 2011; pp 409-420.
(16) Davies, P. L. Trends in Biochemical Sciences; Elsevier: 2014; pp $548-555$.

(17) Sidebottom, C.; Buckley, S.; Pudney, P.; Twigg, S.; Jarman, C.; Holt, C.; Telford, J.; McArthur, A.; Worrall, D.; Hubbard, R.; Lillford, P. Nature 2000, 406 (6793), 256.

(18) Biggs, C. I.; Bailey, T. L.; Ben Graham; Stubbs, C.; Fayter, A.; Gibson, M. I. Nat. Commun. 2017, 8 (1), 1546.

(19) Chao, H.; Davies, P. L.; Carpenter, J. F. J. Exp. Biol. 1996, 199 (Pt 9), 2071-2076.

(20) Carpenter, J. F.; Hansen, T. N. Proc. Natl. Acad. Sci. U. S. A. 1992, 89 (19), 8953-8957.

(21) Gibson, M. I. Polym. Chem. 2010, 1 (8), 1141-1152.

(22) Graham, B.; Fayter, A. E. R.; Houston, J. E.; Evans, R. C.; Gibson, M. I. J. Am. Chem. Soc. 2018, 140 (17), 5682-5685.

(23) Deller, R. C.; Vatish, M.; Mitchell, D. A.; Gibson, M. I. Nat. Commun. 2014, 5, 3244.

(24) Mitchell, D. E.; Lovett, J. R.; Armes, S. P.; Gibson, M. I. Angew. Chem., Int. Ed. 2016, 55 (8), 2801-2804.

(25) Mitchell, D. E.; Cameron, N. R.; Gibson, M. I. Chem. Commun. 2015, 51 (65), 12977-12980.

(26) Graham, B.; Bailey, T. L.; Healey, J. R. J.; Marcellini, M.; Deville, S.; Gibson, M. I. Angew. Chem., Int. Ed. 2017, 56, 1594115944.

(27) Deller, R. C.; Pessin, J. E.; Vatish, M.; Mitchell, D. A.; Gibson, M. I. Biomater. Sci. 2016, 4, 1079.

(28) Matsumura, K.; Bae, J. Y.; Kim, H. H.; Hyon, S. H. Cryobiology 2011, 63 (2), 76-83.

(29) Congdon, T.; Notman, R.; Gibson, M. I. Biomacromolecules 2013, 14 (5), 1578-1586.

(30) Vail, N. S.; Stubbs, C.; Biggs, C. I.; Gibson, M. I. ACS Macro Lett. 2017, 6 (9), 1001-1004.

(31) Inada, T.; Lu, S. S. Cryst. Growth Des. 2003, 3 (5), 747-752.

(32) Burkey, A. A.; Riley, C. L.; Wang, L. K.; Hatridge, T. A.; Lynd, N. A. Biomacromolecules 2018, 19 (1), 248-255.

(33) Inada, T.; Modak, P. R. Chem. Eng. Sci. 2006, 61 (10), 31493158.

(34) Budke, C.; Koop, T. ChemPhysChem 2006, 7 (12), 2601-2606.

(35) Drori, R.; Li, C.; Hu, C.; Raiteri, P.; Rohl, A.; Ward, M. D.; Kahr, B. J. Am. Chem. Soc. 2016, 138 (40), 13396-13401.

(36) Stubbs, C.; Lipecki, J.; Gibson, M. I. Biomacromolecules 2017, 18 (1), 295-302.

(37) Rajan, R.; Hayashi, F.; Nagashima, T.; Matsumura, K. Biomacromolecules 2016, 17 (5), 1882-1893.

(38) Leclère, M.; Kwok, B. K.; Wu, L. K.; Allan, D. S.; Ben, R. N. Bioconjugate Chem. 2011, 22 (9), 1804-1810.

(39) Mangiagalli, M.; Bar-Dolev, M.; Tedesco, P.; Natalello, A.; Kaleda, A.; Brocca, S.; de Pascale, D.; Pucciarelli, S.; Miceli, C.; Braslavsky, I.; Lotti, M. FEBS J. 2017, 284 (1), 163-177.

(40) Mitchell, D. E.; Lovett, J. R.; Armes, S. P.; Gibson, M. I. Angew. Chem., Int. Ed. 2016, 55 (8), 2801-2804.

(41) Deller, R. C.; Vatish, M.; Mitchell, D. A.; Gibson, M. I. ACS Biomater. Sci. Eng. 2015, 1 (9), 789-794.

(42) Matsumura, K.; Hyon, S. H. Biomaterials 2009, 30 (27), 48424849.

(43) Davies, P. L.; Sykes, B. D. Curr. Opin. Struct. Biol. 1997, 7 (6), $828-834$.

(44) DeMerlis, C. C.; Schoneker, D. R. Food Chem. Toxicol. 2003, 41 (3), 319-326.

(45) D'souza, A. A.; Shegokar, R. Expert Opin. Drug Delivery 2016, 13 (9), 1257-1275.

(46) DeMerlis, C. C.; Schoneker, D. R. Food Chem. Toxicol. 2003, 41, 319-326. 